\title{
STUDY OF RECOMBINATION AND ELECTRIC PROPERTIES OF $p$-Si CRYSTALS IRRADIATED WITH ELECTRONS
}

\author{
T.A. PAGAVA, D.Z. KHOCHOLAVA, N.I. MAISURADZE, \\ L.S. CHKHARTISHVILI
}

PACS 61.72.CC, 61.72.Ji,

Specimens of $p$-Si irradiated with $8-\mathrm{MeV}$ electrons have been studied. Various radiation-induced defects have been identified by analyzing the temperature dependences of the hole concentration and the curves of isochronous annealing of irradiated specimens. By analyzing the dependences of the lifetime of minority charge carriers $\tau$, the specific resistance $\rho$, the hole concentration $p$, and the Hall mobility $\mu_{\mathrm{H}}$ on the isochronous annealing temperature $T_{\text {ann }}$, the annealing-induced features in the behavior of $p$ and $\mu_{\mathrm{H}}$ are revealed. We determined which radiation-induced defects are recombination centers. From the curves of isochronous annealing carried out during various time intervals, the activation energies of annealing, $E_{\text {ann }}$, are determined for a number of radiation-induced defects.

\section{Introduction}

Primary radiation-induced defects (RIDs) in $n$-Si crystals are known [1] to be carriers of elementary charges of either sign. This circumstance gives rise to an increase in the recombination rate of Frenkel pairs and, respectively, to a reduction of the efficiency of secondary-RID insertion. In $p$-Si crystals, the primary RIDs, at the moment of their formation, are carriers of elementary charges of the same sign, which reduces the rate of their recombination and increases the efficiency of secondary-RID insertion. This fact may probably be responsible for the abundance and the diversity of secondary RIDs in $p$-Si crystals. It should be noted that the secondary RIDs are formed not only during the irradiation, but also in the course of isochronous annealing (IA).

Different parameters of a semiconductor response differently to the concentration of secondary RIDs. For instance, the lifetime of the minority charge carriers, $\tau$, is more sensitive to the presence of defects than the specific resistance $\rho$ and the charge carrier mobility $\mu_{\mathrm{H}}[2]$. The results of work [3] testify that, at the irradiation of Si crystals, the lifetime of minority charge carriers, $\tau$, changes substantially. In work [4], the observable increase and the subsequent reduction of $\tau$ in $n$-Si, as the exposure dose $\Phi$ grew, was explained by a diminishing of the number of recombination centers (RCs), which are of the chemical nature ( $\mathrm{Au}, \mathrm{Cu}$, and so on), owing to their relocation at irradiation into interstitial positions, as well as by the growth of the number of RCs inserted at irradiation and the reverse dissolution of active impurity in nonequilibrium vacancies at large $\Phi$ 's. The observed increase of $\tau$ from 20 to $70 \mu \mathrm{s}$ in $p$-Si crystals fabricated with the use of the zone melting technique, when the dose $\Phi$ was varied from $2 \times 10^{14}$ to $8 \times 10^{15} \mathrm{~cm}^{-2}$, was explained by the authors of work [5] by a reduction of the free charge carrier concentration. In $p$-Si specimens obtained by the Czochralski method, the value of $\tau$ was not restored even after the irradiation to the doses, at which the concentration of charge carriers diminished to $10^{11} \mathrm{~cm}^{-3}$. According to the viewpoint of the authors of work [6], in $p$-Si fabricated using the zone melting technique, there emerge the defects with deep levels, whereas in the crystals obtained using the Czochralski method, besides RCs with deep energy levels, there also arise RCs with shallow levels, which govern the degradation of $\tau$. In work [7], it was shown that $\tau$ decreases even at such exposure doses $\left(\Phi \approx 10^{10} \div 10^{11} \mathrm{~cm}^{-2}\right)$, when the specific resistance $\rho$ practically does not change. A reduction of $\tau$ from 90 to about $20 \mu$ s was explained by a continu- 


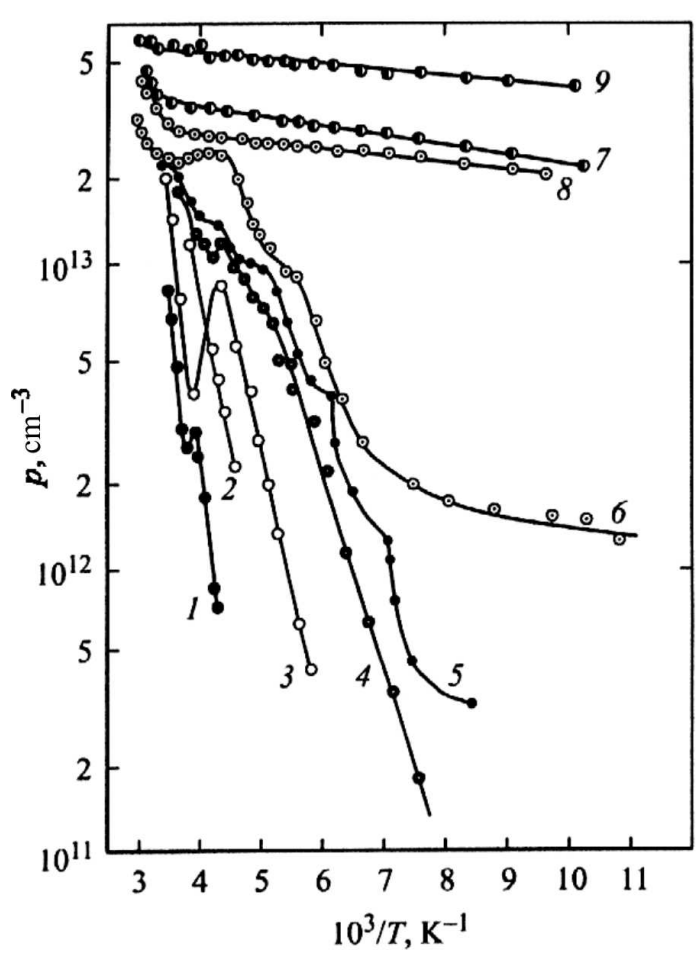

Fig. 1. Temperature dependences of the hole concentration $p$ in a $p$-Si crystal irradiated with electrons. Dependence 1 was obtained before the specimen annealing. The annealing temperature $T_{\text {ann }}=$ 100 (2), 170 (3), 240 (4), 270 (5), 300 (6), 400 (7), 500 (8), and $600{ }^{\circ} \mathrm{C}(9)$

ous increase in the concentration of recombination-active RIDs.

This work is aimed at identifying those defects by determining their energy spectrum, thermal stability, and annealing activation energy. We also made attempt to determine which centers are responsible for a variation of $\tau$. For this purpose, we studied the dependences of the parameters $\tau, \rho, p$, and $\mu_{\mathrm{H}}$ on the IA temperature $\left(T_{\text {ann }}\right)$ in irradiated $p$-Si crystals.

\section{Experimental Part}

We studied specimens of single-crystalline silicon obtained using the zone melting technique, with a hole concentration of $6 \times 10^{13} \mathrm{~cm}^{-3}$, a density of growth dislocations of $10^{3}-10^{4} \mathrm{~cm}^{-2}$, and the initial lifetime of charge carriers $\tau_{\text {init }} \approx 100 \mu \mathrm{s}$. The specimens to study were irradiated with electrons with an energy of $8 \mathrm{MeV}$ at room temperature. The exposure dose, $\Phi \approx 5 \times 10^{15} \mathrm{~cm}^{-2}$, was so selected that the charge carrier lifetime in irradiated specimens was $\tau_{\text {irr }} \approx \tau_{\text {init }}$. The density of electron flow was $\phi=1 \times 10^{12} \mathrm{~cm}^{-2} \mathrm{~s}^{-1}$. The isochronous annealing of irradiated crystals was carried out in the temperature interval $T_{\text {ann }} \approx 80 \div 600{ }^{\circ} \mathrm{C}$ with an increment of $10{ }^{\circ} \mathrm{C}$. The specimen holding time at a fixed temperature was equal to $10 \mathrm{~min}$. After every IA cycle, the parameters $\tau, \rho, p$, and $\mu_{\mathrm{H}}$ were measured. The time $\tau$ was measured by the photoconductivity damping technique.

The excess concentration of charge carriers was created by illuminating the studied specimen with a pulsed flow of white polychromatic light transmitted through a filter. The latter was a plane-parallel polished silicon plate. To exclude the influence of sticking centers arising in the studied specimens at their irradiation, the specimens were illuminated with a continuous flux of white light in the course of measurements. We measured the volume photo-emf along the irradiated specimen and found no heterogeneity that could affect the results of $\tau$-measurements. The amounts of excess charge carriers $(\Delta n$ and $\Delta p)$, which were determined from the voltage change across the loading resistance connected in series with the examined specimen, did not exceed a few percent of the equilibrium hole concentration in this specimen, $p_{0}$, i.e. $\tau$ was measured under the condition of low injection level, $\Delta n=\Delta p \ll p_{0}$. The quantities $\tau, \rho$, and $\mu_{\mathrm{H}}$ were measured at a temperature of $300 \mathrm{~K}$. The concentration $p$ was measured by the Hall method in the temperature interval 77-300 K. Ohmic contacts for carrying out measurements were created by rubbing aluminum into the surface of the specimen under study.

The change of $p$ in the course of IA was determined from the curves $p\left(10^{3} / T\right)$ at $260 \mathrm{~K}$. The measurement error for this quantity did not exceed $10 \%$. The energy levels of defects, $\Delta E_{i}$, were determined, by assuming that $\varepsilon_{\mathrm{F}}=\Delta E_{i}$, where $\varepsilon_{\mathrm{F}}$ is the Fermi level, and using the formula

$p=N_{v} F_{1 / 2}\left(\frac{\varepsilon_{\mathrm{F}}}{k T}\right)$,

where $N_{v}$ is the effective density of states in the valence band, and $F_{1 / 2}(x)$ the Fermi-Dirac integral. The corresponding sections in the dependences $p=f\left(10^{3} / T\right)$ were selected with regard for the depletion degree of a definite level and the degeneracy order of the valence band in silicon (Fig. 1, curves 5 and 6 ). In the strongly compensated specimens, the $\Delta E_{i}$-values were determined from the slope of the dependences $p=f\left(10^{3} / T\right.$ ) (Fig. 1, curves 1 to 4$)$. The concentrations of various RIDs after every IA cycle were calculated with the use of the step-like dependences $p=f\left(10^{3} / T\right)$ and $p=f\left(T_{\text {ann }}\right)$ 


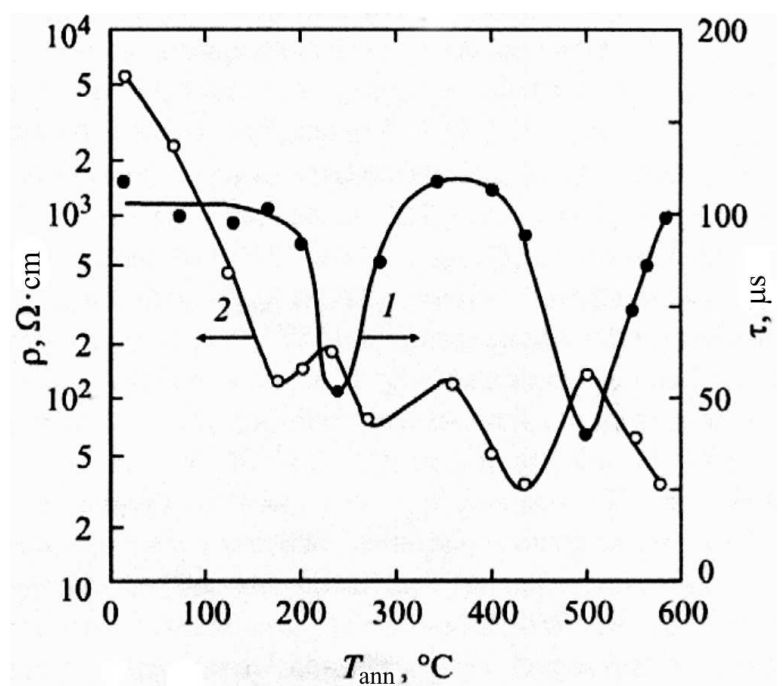

Fig. 2. Dependences of the lifetime of minority charge carriers (1) and the specific resistance (2) in $p$-Si crystals irradiated by electrons on the isochronous annealing temperature $T_{\text {ann }} . T \approx$ $300 \mathrm{~K}$

in the temperature intervals $77-300 \mathrm{~K}$ and $20-600 \mathrm{~K}$, respectively.

\section{Experimental Results and Their Discussion}

In Fig. 2, the dependences of the $\tau$ - (curve 1) and $\rho$ values (curve 2) measured at $300 \mathrm{~K}$ on the IA temperature $T_{\text {ann }}$ are depicted. Figure 3 demonstrates the same dependences, but for the concentration $p$ (curve 1) and the mobility $\mu_{\mathrm{H}}$ (curve 2). As is seen from the latter figure, the defects with the level $\Delta E=E_{v}+0.28 \pm 0.028 \mathrm{eV}$ (curve 3) were annealed in the temperature interval $T_{\text {ann }}=20 \div 110{ }^{\circ} \mathrm{C}$. The concentration of those defects was $N_{3}=3 \times 10^{12} \mathrm{~cm}^{-2}$. They were identified as interstitial atoms of carbon, $\mathrm{C}_{t}$ [8]. The variation of the hole concentration in this temperature interval (curve 1, $\Delta p_{1} \approx 6 \cdot 10^{12} \mathrm{~cm}^{-3}$ ) was twice as large as the concentration of $\mathrm{C}_{i}$ atoms. This circumstance testifies to the fact that other defects were also annealed in this temperature interval. As such, there can be tetravacancies $V_{4}$ [9]. It is probable that a drastic enhancement of the mobility $\mu_{\mathrm{H}}$ in the interval $20-160{ }^{\circ} \mathrm{C}$ (curve 2 in Fig. 3) was associated with the annealing of multivacancy centers $V_{4}$. It should be noted that the reconstruction and the annealing of the defect-impurity shell of disordered regions also took place in this temperature interval, with the practically invariable parameter $\tau$ (Fig. 2, curve 1 ).

A drastic growth of $p$ in the range $T_{\text {ann }} \approx 170-200{ }^{\circ} \mathrm{C}$ is related to the annealing of defects with the energy level $E_{v}+0.45 \pm 0.045 \mathrm{eV}$ and the concentration $N_{\mathrm{RID}} \approx$

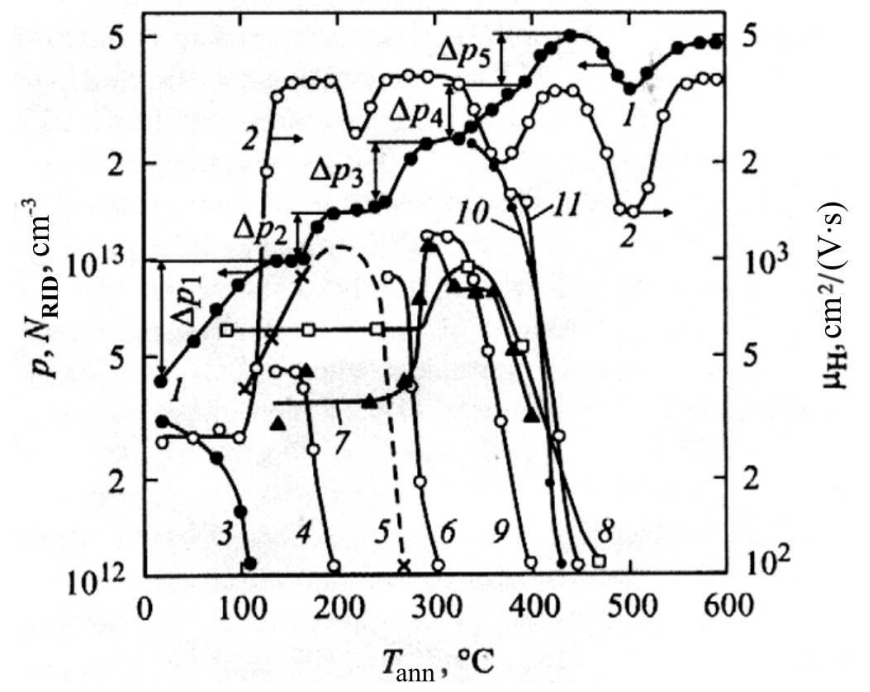

Fig. 3. Variations of the hole concentration $p(1)$, Hall mobility $\mu_{\mathrm{H}}$ of majority charge carriers (2), and concentration of some radiation-induced defects ( 3 to 11 ) in the course of isochronous annealing of $p$-Si crystals irradiated with electrons

$5 \times 10^{12} \mathrm{~cm}^{-3}$ (Fig. 3, curves 1 and 4). This level belongs to the complex $V+\mathrm{B}[10]$.

According to the results of our calculations, the disordered regions (DRs) with the effective radius $R_{\text {eff }} \approx$ $5 \times 10^{3} \AA$ and a concentration of $6 \times 10^{13} \mathrm{~cm}^{-3}$ were formed in silicon crystals of the $p$-type irradiated by 8 $\mathrm{MeV}$ electrons. Vacancies, which are products of the decay of $V+\mathrm{B}$ complexes, were effectively absorbed by DRs, which resulted in an increase of $R_{\text {eff }}$. At $T_{\text {ann }} \approx 220{ }^{\circ} \mathrm{C}$, the annealing of DRs begins [11], and $R_{\text {eff }}$ starts to diminish. This phenomenon can be used to explain a minimum at $T_{\text {ann }} \approx 230{ }^{\circ} \mathrm{C}$ in the dependence $\mu_{\mathrm{H}}\left(T_{\text {ann }}\right)$ (Fig. 3, curve 2) and a maximum in the dependence $\rho\left(T_{\text {ann }}\right)$ (Fig. 2, curve 2$)$.

In the interval $T_{\text {ann }} \approx 100-160{ }^{\circ} \mathrm{C}$, an increase in the concentration of centers with the level $E_{v}+0.18 \pm$ $0.018 \mathrm{eV}$ was observed (Fig. 3, curve 5), which may have a maximum at $220{ }^{\circ} \mathrm{C}$ (we did not manage to trace the variations in the concentration of these centers in the temperature interval $170-260{ }^{\circ} \mathrm{C}$ ). In the interval around $T_{\text {ann }} \approx 270{ }^{\circ} \mathrm{C}$, the centers were completely annealed. The level $E_{v}+0.18 \pm 0.018 \mathrm{eV}$ belongs to interstitial boron atoms, $\mathrm{B}_{i}$, formed in the course of irradiation following the Watkins reaction $\mathrm{B}_{s}+I \rightarrow \mathrm{B}_{i}$ $[12,13]$. The growth of the $\mathrm{B}_{i}$-concentration may probably be associated with the annealing of $V+\mathrm{B}$ complexes. The $\mathrm{B}_{i}$-concentration grew before the annealing of $V+\mathrm{B}$ complexes started, and the maximum $\mathrm{B}_{i}$-concentration was twice the concentration of $V+\mathrm{B}$ complexes. This 
fact points to the existence of other mechanisms of $\mathrm{B}_{i^{-}}$ formation. Probably, the source of $\mathrm{B}_{i}$ before the annealing of $V+\mathrm{B}$ complexes is the complex $\mathrm{C}+\mathrm{B}$, which was annealed, in the opinion of the authors of work [8], in the interval about $90{ }^{\circ} \mathrm{C}$. The change of the $\mathrm{B}_{i^{-}}$ concentration did not affect the hole concentration $p$ at $300 \mathrm{~K}$, but brought about a considerable variation of $\tau$ (Fig. 2, curve 1). The constant value of $p$ in the course of $\mathrm{B}_{i}$-defect annealing testifies that those defects did not return into lattice sites, which would have led to an increase of $p$, but moved to other drains, forming shallow donors, for instance, $V+\mathrm{O}+\mathrm{B}_{i}[14]$.

In the temperature interval $T_{\text {ann }} \approx 200 \div 300{ }^{\circ} \mathrm{C}$, the centers with the level $\Delta E_{i}=E_{v}+0.28 \pm 0.028 \mathrm{eV}$ and a concentration of about $9 \times 10^{12} \mathrm{~cm}^{-3}$ were annealed (Fig. 3, curves 1 and 6 ). Judging by the magnitudes of $T_{\text {ann }}$ and $\Delta E_{i}$, those centers are divacancies (DVs) $V_{2}$ [10]. The annealing of DVs was accompanied by a drastic increase of $\tau$ and a reduction of $\rho$ (Fig. 2, curves 1 and 2). The concentration of annealed DVs $N_{V_{2}} \approx \Delta p_{3} \approx 9 \times 10^{12} \mathrm{~cm}^{-3}$ (Fig. 3, curve 1). This testifies that the DV decay was not accompanied by the formation of other deep donors, which would have reduced the value of $\Delta p_{3}$ and broken the equality between those quantities. In the course of DV annealing, an increase in the concentration of defects with the level $\Delta E_{i}=E_{v}+0.22 \pm 0.022 \mathrm{eV}$ was observed (Fig. 3, curve 7). This defect was annealed in two stages: in the intervals $T_{\text {ann }} \approx 300-330{ }^{\circ} \mathrm{C}$ and $360-400{ }^{\circ} \mathrm{C}$. It is known [15] that an unknown center, which is formed in the course of irradiation, was annealed at the first stage, and the complex "a doping boron atom + a divacancy" $\left(\mathrm{B}_{s} V_{2}\right)$ at the second one. This complex was formed as a result of the DV conversion according to the reaction $\mathrm{B}_{s}+V_{2} \rightarrow \mathrm{B}_{s} V_{2}$ in the temperature range $270-290{ }^{\circ} \mathrm{C}$. Its ionization energy coincided with that of the defect annealed at the first stage. The first annealing stage of this center was accompanied by an increase in the concentration of the defect with the level $E_{v}+0.20 \pm 0.02 \mathrm{eV}$, which had a maximum at $340{ }^{\circ} \mathrm{C}$ and became completely annealed at about $470{ }^{\circ} \mathrm{C}$. The nature of those two defects is unknown. We can only say that they contain vacancies, because their concentrations grew in the course of DV annealing. Judging by the magnitudes $E_{\text {ann }} \approx 2.33 \pm 0.233 \mathrm{eV}$ and $T_{\text {ann }} \approx 470{ }^{\circ} \mathrm{C}$, the center with the level $E_{v}+0.20 \pm 0.02 \mathrm{eV}$ seems to be a multicomponent defect [9] (Fig. 3, curves 7 and 8). These defects did not influence $\tau, \rho, p$, and $\mu_{\mathrm{H}}$ at $T \approx 300 \mathrm{~K}$. Centers with $\Delta E_{i}=0.40 \pm 0.04 \mathrm{eV}$ were annealed in the same temperature interval (Fig. 3, curve 9 ). Judging by the magnitudes of $\Delta E_{i}$ and $T_{\text {ann }}$, they are multicomponent complexes of the type $V_{3}+\mathrm{O}$ or $V_{2}+\mathrm{O}_{2}[9,16]$. They did not affect $\mu_{\mathrm{H}}$ and $\tau$ (see Figs. 2 and 3). At $T_{\text {ann }} \approx 340{ }^{\circ} \mathrm{C}$, the annealing of unknown $X$-centers with $\Delta E_{i}=E_{v}+0.35 \pm 0.035 \mathrm{eV}$ started, as well as an increase of the hole concentration $p$ (Fig. 3, curves 1 and 10). This level, judging by the magnitudes of $\Delta E_{i}$ and $T_{\text {ann }}$, belongs to the $K$-center, which is formed as a result of the joining of $V_{2}$ to the COcenter [17]. In the opinion of the authors of work [18], this complex has the structure $\mathrm{C}+\mathrm{O}_{2}+V$. The authors of work [19] consider that the $K$-center includes oxygen, carbon, and a vacancy, $\mathrm{O}+\mathrm{C}+V$. However, according to work [20], the $K$-center is formed only by oxygen and carbon, $\mathrm{C}+\mathrm{O}$. The concentration of those centers were $N_{K} \approx 2.5 \times 10^{13} \mathrm{~cm}^{-3}$ (Fig. 3, curve 10).

Specimens for studying were obtained using the zone melting technique. It is known [21] that the concentration $N_{0} \approx 10^{16} \mathrm{~cm}^{-3}$ in such specimens is a few orders of magnitude lower than that in specimens obtained using the Czochralski method, $N_{0} \approx 10^{18} \mathrm{~cm}^{-3}$. Hence, defects of the $\mathrm{C}_{i} \mathrm{C}_{s}$ type (interstitial carbon + carbon at the lattice site) rather than CO-centers are mainly formed in such specimens in the course of irradiation. Therefore, the formation of $K$-centers following the reaction $\mathrm{CO}+V_{2} \rightarrow \mathrm{COV}_{2}$ is impossible. We name these unknown defects $X$-centers. It should be noted that the concentration of $X$-centers is twice as high as the DV concentration.

In the interval $T_{\text {ann }} \approx 400 \div 450{ }^{\circ} \mathrm{C}$, the annealing of defects with the level $E_{v}+0.36 \pm 0.036 \mathrm{eV}$ was observed. The concentration of this defect was $\Delta p_{s} \approx$ $1.5 \times 10^{13} \mathrm{~cm}^{-3}$ (Fig. 3, curves 1 and 11). Within the determination error limits, the defects with the levels $E_{v}+0.35 \pm 0.035 \mathrm{eV}$ and $E_{v}+0.36 \pm 0.036 \mathrm{eV}$ could not be distinguished, but the annealing of defects with the level $E_{v}+0.36 \pm 0.036 \mathrm{eV}$ started at a higher temperature, and a drastic increase of the hole concentration was observed in the same temperature interval $400-440{ }^{\circ} \mathrm{C}$ (Fig. 3, curve 1). These defects together with $X$-centers are capable of the effective hole scattering, which can explain a minimum in the dependence $\mu_{\mathrm{H}}\left(T_{\mathrm{ann}}\right)$ (Fig. 3, curve 2) and, respectively, a maximum in the dependence $\rho\left(T_{\text {ann }}\right)$ at $T_{\text {ann }} \approx 360{ }^{\circ} \mathrm{C}$ (Fig. 2, curve 2). The dependence $\tau\left(T_{\mathrm{ann}}\right)$ had a maximum at this temperature (Fig. 2, curve 1). The growth of $\mu_{\mathrm{H}}$ and $\rho$ in the interval $T_{\text {ann }} \approx 360 \div 420{ }^{\circ} \mathrm{C}$ was responsible for a drastic reduction of $\rho$ here. The total concentration of defects with the levels $E_{v}+0.40 \pm 0.04 \mathrm{eV}, E_{v}+0.35 \pm 0,035 \mathrm{eV}$, and $E_{v}+0.36 \pm 0,036 \mathrm{eV}$, which were annealed in the temperature interval $340-440{ }^{\circ} \mathrm{C}$, was higher than a variation of the hole concentration $\Delta p=\Delta p_{4}+\Delta p_{s}$ in this anneal- 
ing temperature interval (Fig. 3). This testifies that the annealing of those defects gave rise to the emergence of deep centers with a high thermal stability, the concentration of which continued to grow after those defects had been annealed. In this case, the following equality is obeyed: $\Delta N_{\mathrm{RID}}=\Delta p+\Delta N_{\mathrm{RID}}^{\prime}$, where $\Delta N_{\mathrm{RID}}$ is the concentration of annealed RIDs, $\Delta p$ the increment of the hole concentration, and $\Delta N_{\mathrm{RID}}^{\prime}$ the concentration of deep donors emerging in the course of IA (one should take into account that $p \geq N_{\mathrm{RID}}+\Delta N_{\mathrm{RID}}^{\prime}$ at any IA temperature. The formation and the annealing of those complexes brought about the appearance of a minimum in the dependence $p\left(T_{\text {ann }}\right)$ at $500{ }^{\circ} \mathrm{C}$. The hole concentration decreased to $3.5 \times 10^{13} \mathrm{~cm}^{-3}$ and, at $T_{\text {ann }}=600{ }^{\circ} \mathrm{C}$, restored its initial value, which it had at $T_{\text {ann }} \approx 450{ }^{\circ} \mathrm{C}$. By comparing curves 8 and 9 in Fig. 1 at $T=200 \mathrm{~K}$, we can determine the concentration of those defects to be equal to $2.5 \times 10^{13} \mathrm{~cm}^{-3}$. At $T_{\text {ann }} \approx 500{ }^{\circ} \mathrm{C}$, the dependences $p\left(T_{\mathrm{ann}}\right)$ and $\mu\left(T_{\mathrm{ann}}\right)$ had minima (Fig. 3$)$, which resulted in the appearance of a maximum in the dependence $\rho\left(T_{\text {ann }}\right)$ (Fig. 2, curve 2). As is seen from Fig. 2 (curve 1 ), the dependence $\tau\left(T_{\text {ann }}\right)$ had a minimum at $T_{\text {ann }} \approx 500{ }^{\circ} \mathrm{C}$ and restored its initial value at $T_{\text {ann }} \approx 600{ }^{\circ} \mathrm{C}$. The defects discussed above, judging by the temperatures of their formation and annealing, were probably multicomponent complexes of the type $V_{3}+\mathrm{O}_{3}$ or $V_{3}+\mathrm{O}_{2}$ with the level $\Delta E_{i}=E_{v}+0.40 \pm 0.04 \mathrm{eV}$ $[9,22]$, which were formed after the decay of complexes $V_{3}+\mathrm{O}$ and $V_{2}+\mathrm{O}_{2}$, as well as centers and defects with the level $\Delta E_{i}=E_{v}+0.36 \pm 0.036 \mathrm{eV}$. The influence of those complexes at $300 \mathrm{~K}$ on the magnitudes of $p, \mu_{\mathrm{H}}$, and $\tau$ allowed us to assume that they are RCs with deep levels, capable of effective hole scattering.

In view of the variety of RIDs, it is difficult to create conditions in irradiated $p$-Si crystals, under which the recombination would completely govern defects of a definite type, which would have allowed us to determine RC parameters from the temperature dependences of $\tau$. For the same reason, the formulation and the solution of kinetic equations in order to determine the parameters $\Delta E_{i}, N_{\mathrm{RID}}$, and $T_{\text {ann }}$ for RIDs formed in $p$-Si crystals in the course of their irradiation and IA are complicated. Nevertheless, a comparison of IA curves for $\tau, \rho, p$, and $\mu_{\mathrm{H}}$ allowed us to assume that $\mathrm{B}_{i}$ and DV defects are responsible for the change of $\tau$ at $300 \mathrm{~K}$ in the course of IA in the range $T_{\text {ann }} \approx 200-300{ }^{\circ} \mathrm{C}$ and multicomponent deep donors $\left(\Delta E_{i}=E_{v}+0.40 \pm 0.04 \mathrm{eV}\right)$ of the $V_{3}+\mathrm{O}_{3}$ or $V_{3}+\mathrm{O}_{2}$ type, which are scattering centers as well, in the range of about $500{ }^{\circ} \mathrm{C}$. The $\mathrm{C}_{i}, V_{4}, V_{3}+\mathrm{O}$, and $V_{2}+\mathrm{O}_{2}$ defects do not possess recombination abilities. The activation energies of annealing for $X$-centers, $\mathrm{C}_{i}$ defects, $V+\mathrm{O}, V_{2}+\mathrm{O}_{2}$, and $V_{2}$ complexes, and defects with the level $\Delta E_{i}=E_{v}+0.20 \pm 0.02 \mathrm{eV}$ were determined from the curves of IA of those centers [23]. According to our estimations, the measurement errors for $E_{\text {ann }}$ did not exceed $10 \%$, so that the values obtained are $0.9 \pm 0.1,0.25 \pm 0.025,1.6 \pm 0.16,2.0 \pm 0.2,1.54 \pm 0.15$, and $2.33 \pm 0.23 \mathrm{eV}$, respectively.

\section{Conclusion}

To summarize, the variations of the lifetime of minority charge carriers $\tau$, the specific resistance $\rho$, the hole concentration $p$, and the Hall mobility $\mu_{\mathrm{H}}$ of majority charge carriers, which take place in $p$-Si crystals irradiated with electrons in the course of their isochronous annealing in the temperature range $T_{\text {ann }} \approx 80-600{ }^{\circ} \mathrm{C}$, have been studied in this work. The analysis of the dependences of $\tau, \rho, p$, and $\mu_{\mathrm{H}}$ on the annealing temperature $T_{\text {ann }}$ allowed us to suppose that interstitial boron atoms $\mathrm{B}_{i}$ and divacancies $V_{2}$ are responsible for an annealing-induced variation of $\tau$ in the interval $T_{\text {ann }} \approx 200-300{ }^{\circ} \mathrm{C}$, which is observed at the temperature $T \approx 300 \mathrm{~K}$, and multicomponent deep donors of the $V_{3}+\mathrm{O}_{3}$ or $V_{3}+\mathrm{O}_{2}$ type with the energy level $\Delta E_{i}=E_{v}+0.40 \pm 0.04 \mathrm{eV}$, which are also scattering centers, in the interval $T_{\text {ann }} \approx 500{ }^{\circ} \mathrm{C}$. Defects $\mathrm{C}_{i}, V_{3}+\mathrm{O}$, and $V_{2}+\mathrm{O}_{2}$ are not recombination centers at $T \approx 300 \mathrm{~K}$. By analyzing the curves of isochronous annealing carried out during various time intervals, the activation energies of annealing of $X$-centers, interstitial carbon atoms $\mathrm{C}_{i}, V+\mathrm{O}$ and $V_{2}+\mathrm{O}_{2}$ complexes, $V_{2}$ divacancies, and defects with the energy level $\Delta E_{i}=E_{v}+0.20 \pm 0.02 \mathrm{eV}$ were determined to equal $0.9 \pm 0.1,0.25 \pm 0.025,1.6 \pm 0.16,2.0 \pm 0.2,1.54 \pm 0.15$, and $2.33 \pm 0.23 \mathrm{eV}$, respectively.

1. L.S. Milevskii and V.S. Garnyk, Fiz. Tekh. Polupr. 13, 1369 (1979).

2. P.A. Borodovskii, A.F. Buldygin, and A.S. Tokarev, Fiz. Tekh. Polupr. 38, 1043 (2004).

3. V.S. Vavilov, S.I. Vintovkin, A.S. Lyutovich et al., Fiz. Tverd. Tela 7, 502 (1965).

4. V.V. Bolotov, V.A. Korotchenko, A.P. Mamontov et al., Fiz. Tekh. Polupr. 14, 2257 (1980).

5. Z.V. Basheleishvili, V.S. Garnyk, S.N. Gorin, and T.A. Pagava, Fiz. Tekh. Polupr. 18, 1714 (1984).

6. V.S. Garnyk and Z.V. Basheleishvili, Fiz. Tekh. Polupr. 24, 1485 (1990).

7. T.A. Pagava, Z.V. Basheleishvili, E.R. Kuteliya, and N.I. Maisuradze, Ukr. Fiz. Zh. 48, 435 (2003).

8. V.N. Gubskaya, P.V. Kuchinskii, and V.M. Lomako, Fiz. Tekh. Polupr. 20, 1055 (1986). 
9. V.V. Emtsev and T.V. Mashovets, Impurities and Point Defects in Semiconductors (Radio i Svyaz, Moscow, 1981) (in Russian).

10. I.D. Konozenko, A.K. Semenyuk, and V.I. Hivrich, Radiation-Induced Effects in Silicon (Kyiv, Naukova Dumka, 1974) (in Russian).

11. Physical Processes in Irradiated Semiconductors, edited by L.S. Smirnov (Nauka, Novosibirsk, 1977) (in Russian).

12. N.V. Kolesnikov, S.E. Mal'khanov, and M.A. Pogarskii, Fiz. Tekh. Polupr. 12, 1836 (1978).

13. V.V. Luk'yanitsa, Fiz. Tekh. Polupr. 33, 921 (1999).

14. M.Yu. Barabanenkov, A.V. Leonov, V.N. Mordkovich, and N.M. Omel'yanskaya, Fiz. Tekh. Polupr. 33, 997 (1999)

15. T.A. Pagava, L.S. Chkhartishvili, N.I. Maisuradze, and E.R. Kuteliya, Ukr. Fiz. Zh. 52, 1162 (2007).

16. J. Bourgoin and M. Lannoo, Point Defects in Semiconductors, Vol. 2: Experimental Aspects (Springer, Berlin, 1983).

17. Y.H. Lee, J.W. Corbet, and K.L. Brover, Phys. Status Solidi A 41, 637 (1977).

18. L.S. Berman, N.A. Vitkovskii, V.N. Lomasov, and V.N. Tkachenko, Fiz. Tekh. Polupr. 24, 2186 (1990).

19. P.M. Mooney, L.J. Cheng, M. Suly, J.D. Gerson, and J.W. Corbett, Phys. Rev. B 15, 386 (1977).

20. C.A. Londos. Jpn. J. Appl. Phys. 27, 2089 (1988).
21. I.I Kolkovskii and V.V. Luk'yanitsa, Fiz. Tekh. Polupr. 31, 405 (1997).

22. Y.H. Lee and J.W. Corbett, Phys. Rev. B 13, 2653 (1976)

23. A.C. Damask and G.J. Dienes, Point Defects in Metals (Gordon and Breach, New York, 1963).

Received 25.02.11.

Translated from Russian by O.I. Voitenko

ДОСЛІДЖЕННЯ РЕКОМБІНАЦІЙНИХ І ЕЛЕКТРИЧНИХ ВЛАСТИВОСТЕЙ КРИСТАЛІВ $p$-Si, ОПРОМІНЕНИХ ЕЛЕКТРОНАМИ

Т.А. Пагава, Д.З. Хочолава, Н.І. Майсурадзе,

Л.С. Чхартішвілі

$\mathrm{P}$ е з ю м е

Досліджено зразки $p$-Si, опромінені електронами з енергією 8 MeB. За температурними залежностями параметрів під час ізохронного відпалу опромінених зразків проведено ідентифікацію різних радіаційних дефектів. На основі аналізу залежностей часу життя неосновних носіїв току $\tau$, питомого опору $\rho$, концентрації $p$ і холлівської рухомості $\mu_{\mathrm{H}}$ від температури ізохронного відпалу $T$ виявлено особливості відпалу $\mu_{\mathrm{H}}$ i $\rho$. Визначено, які радіаційні дефекти є рекомбінаційними центрами.

За кривими ізохронного відпалу, проведених при різних інтервалах часу, визначено енергії активації відпалу $E$ деяких радіаційних дефектів. 